\title{
Bem viver, Ubuntu e a Sociomuseologia: contribuições para descolonizar a Educação Museal
}

\author{
Bien vivir, Ubuntu y la Sociomuseología: contribuciones para descolonizar la Educación Museal \\ Good living, Ubuntu and sociomuseology: contributions to decolonize museum education
}

Juliana Maria de Siqueira ${ }^{1}$

Recibido: 4/9/2016 / Aprobado: 23/5/2017

\begin{abstract}
Resumo
A Sociomuseologia é permanentemente instigada a expandir e aprofundar seus conceitos e suas práticas. Se continua relevante o propósito da Mesa Redonda de Santiago do Chile - de firmar o compromisso dos museus com a vida, a dignidade humana e a justiça social - no cotidiano das instituições isso é em alguma medida realizado e simultaneamente negado. Nos cenários de opressão, aflora sempre uma resistência; onde quer que a liberdade se realize, será possível ampliá-la. Por meio da reflexividade, descobrimos os pontos cegos que nos impedem de perceber as exclusões e os limites desse fazer-conhecer. Olhar para o campo desde a perspectiva dos povos originários do Sul pode contribuir para sua descolonização. Esta comunicação tem como intento explorar os aportes da Biologia do Conhecer, do BemViver e do Ubuntu para a fundamentação da Educação Museal numa mirada participativa e emancipadora.
\end{abstract}

Palavras-Chave: Bem-Viver, biologia do conhecer, educação museal, sociomuseologia, Ubuntu.

\section{Resumen}

\begin{abstract}
La Sociomuseología es con frecuencia orientada a expandir y profundizar sus conceptos y sus prácticas. Si continúa siendo relevante el propósito de la Mesa Redonda de Santiago de Chile -de firmar el compromiso de los museos con la vida, la dignidad humana y la justicia social- en el cotidiano de las instituciones eso es en alguna medida realizado y simultáneamente negado. En los escenarios de opresión, aflora siempre una resistencia; dondequiera que la libertad se realice, será posible ampliarla. Por medio de la reflexividad, se descubren los puntos ciegos que nos impiden percibir las exclusiones y los límites de ese hacer-conocer. Mirar hacia el campo desde la perspectiva de los pueblos originarios del Sur puede contribuir a su descolonización. Esta comunicación tiene como objetivo explorar los aportes de la Biología del Conocer, del Bien-Vivir y de Ubuntu para la fundamentación de la Educación Museal en una mirada participativa y emancipadora.
\end{abstract}

Palabras clave: Bienestar, biología del conoce, educación museal, sociomuseología, Ubuntu.

\footnotetext{
*Este texto corresponde con la temática de la ponencia presentada en el III Seminario Internacional Culturas y Desarrollo, III Encuentro de la Red de Interculturalidad, IV Encuentro de la Red de Trabajo con Pueblos Indígenas, IV Encuentro sobre Sociedades en Cambio, Territorios, Culturas y Buen Vivir, Desafíos desde las identidades y Saberes Diversos, realizado el 20, 21 y 22 de julio de 2016, en la Universidad Nacional, campus Omar Dengo, Heredia y en la Universidad de Costa Rica, Sede de Occidente, San Ramón, ahora en formato de artículo científico, en versión completa extendida.

${ }^{1}$ Doctoranda en Museología en la Universidad Lusófona de Humanidades y Tecnologías (Lisboa, Portugal); magister en Ciencias de la Comunicación por la Universidad de São Paulo. Especialista Cultural en el Museo de la Imagen y del Sonido de Campinas (SP, Brasil). Correo electrónico: ju.de.siqueira@gmail.com
} 


\title{
Abstract
}

\begin{abstract}
Sociomuseology science often concerns about concepts and practices to expand and deepen. If the purpose of the Round Table of Santiago, Chile still remains relevant, that is, to sign in a commitment of museums with the life, the human dignity and social justice, in the daily routine of the institutions, that is, accomplished and to some extent denied simultaneously. In scenarios of oppression, a resistance will always come up; wherever freedom is made, it will be possible to be extended. By means of reflexivity, blind spots that prevent us of perceiving the exclusions and the limits of that thing of doing and knowing. Looking to the land from the native villagers' perspective from the South, it may help to their decolonization. This communication has an objective, that is, to explore the Biology of Knowledge contributions, Good-Living and Ubuntu in order to establish the theoretical foundation of Museum Education in a participative and emancipatory glance.
\end{abstract}

Keywords: Good-living, biology of knowledge, museum education, sociomuseology, Ubuntu.

\section{Educação Museal, o ponto de partida}

Esta comunicação partilha algumas pistas exploradas na pesquisa de doutorado em Museologia, realizada na Universidade Lusófona de Humanidades e Tecnologias. O objetivo da investigação é explorar os fundamentos epistemológicos, teóricos e metodológicos de um campo de estudos e intervenção social em consolidação no Brasil: a Educação Museal. Partindo das conclusões dos estudos realizados por Martins (2011) e da experiência de onze anos no desenvolvimento de programas educativos junto ao Museu da Imagem e do Som de Campinas (SP, Brasil), assumi como hipótese que somente se pode tratar de Educação Museal no campo da Sociomuseologia. Em outros termos, só existe especificidade no aprendizado que se poderia nomear museal quando este se refere à apropriação do processo museológico por meio da participação e do protagonismo comunitário no conhecer-produzir o patrimônio e no fazer o museu. Nos demais casos, temos uma aprendizagem melhor definida como Educação em Museus, ou simplesmente "processos sociais nos quais as instituições museais se encontram inseridas e que determinam um funcionamento específico para essa educação" (Martins, 2011, p. 363).

Nesses termos, o objetivo de investigar os fundamentos epistemológicos da Educação Museal levou-me a buscar teorias do conhecimento condizentes com os princípios, objetivos e práticas da Sociomuseologia. Isso significa adotar perspectivas que tomem o processo cognitivo como ação dialógica humanizadora, preterindo concepções cientificistas, puramente objetivistas e pretensamente neutras. Dado o compromisso com a realidade social em que estou inserida, voltei o olhar às Epistemologias do Sul. Mostraram-se promissoras a Biologia do Conhecer, abordagem científica desenvolvida por Humberto Maturana Romesín e seus colaboradores, o Bem-Viver, ontologia baseada na cosmovisão dos povos originários dos Andes, e a filosofia africana Ubuntu.

Na investigação em curso, venho procedendo o cruzamento entre essas três perspectivas. Não se busca o seu alinhamento e homogeneização, tampouco sua oposição. Procura-se a percepção de pontos comuns e especificidades, convergências e singularidades que iluminam as tensões sutis e ressaltam as diferenças de potencial de cada abordagem para a concepção da aprendizagem no processo museológico social. No âmbito deste artigo, adotarei método comparativo similar ao empregado por Carvalho (2010), que busca analisar, por meio de seis dimensões, complementaridades e cumplicidades entre teorias filosóficas. Tais dimensões são a visão da ciência ou do conhecimento; a relação sujeito-objeto; o critério de validação; a regularidade da realidade; a neutralidade e objetividade; e a construção da ciência e do conhecimento. Como resultado dessa interlocução, vem emergindo uma concepção do processo sociomuseológico como ato cognitivo, adequada para se compreender a Educação Museal. 


\section{Biologia do Conhecer}

Humberto Maturana Romesín, biólogo e neurocientista chileno, concebeu a Biologia do Conhecer no final dos anos 1960 a partir de seu trabalho em diferentes frentes de estudos, exploradas desde meados dos anos 50 . Um primeiro aspecto de sua teoria diz respeito ao funcionamento do sistema nervoso, compreendido como um sistema fechado, operando sem inputs e outputs que impliquem a representação mental da realidade externa, mas por meio da configuração do mundo em que vivemos pelo seu nomear. Explorando os fenômenos da percepção cromática como constância e sombra de cores, Maturana compreendeu o papel fundamental da linguagem no conhecimento, ao concluir que a experiência da percepção da cor era dada pela correlação entre a atividade retiniana e o seu nomear, independentemente das configurações espectrais dos estímulos luminosos externos. Outro campo de interesses de Maturana eram as relações constitutivas dos seres vivos, às quais ele identificou como autopoiéticas, isto é, sistemas de organização circular em que os processos que constituem os seres vivos como unidade conservam-se a si mesmos ao produzirem seus componentes. Da convergência entre esses estudos emergiu a Biologia do Conhecer, delineada em 1969 no artigo Neurophysiology of cognition, endereçado a um congresso de Antropologia realizado na Universidade de Illinois, nos Estados Unidos. Em síntese, ele demonstrava "como o fenômeno do conhecer é um fenômeno do operar do ser vivo em congruência com suas circunstâncias, e, portanto, é um comentário do observador sobre este operar" (Maturana R. et al, 1997, p. 34). Essa teoria, que pretende dar conta do funcionamento biológico implícito aos processos cognitivos, é simultaneamente uma filosofia, na medida em que Maturana constitui "uma teoria do viver e do observar" (Graciano \& Magro, 1997, p. 29) com importantes consequências éticas.

\subsection{Visão do conhecimento}

Para se compreender o conhecimento é necessário considerar a biologia do ser que conhece, isto é, perguntar pelo observador e pelas condições que constituem o seu observar. E o que se pode afirmar sobre isso é que nenhum observador tem um acesso à realidade privilegiado em relação aos demais e, portanto, ninguém detém um conhecimento mais verdadeiro que o dos outros. Na experiência, somos igualmente incapazes de distinguir entre ilusão e percepção (Maturana R., 2009, p. 44). Assim, o que produzimos é um caminho explicativo da experiência, um discurso ou comentário, válido enquanto for congruente com o agir dos seres em seu meio. O conhecimento, pois, é um processo de reflexividade na linguagem, que nos constitui como observadores. Na ciência, as explicações não requerem a suposição de "um mundo objetivo independente de nossos atos cognitivos e acessível ao nosso conhecimento" (Maturana R. et al, 1997, p. 77). Exigem, contudo, o aceite pela comunidade científica, na satisfação dos critérios de validação por ela definidos. O que distingue um processo cognitivo como científico é o fato de ele produzir o mecanismo gerador dos fenômenos que deseja explicar, isto é, o próprio método científico.

\subsection{Relação sujeito-objeto}

$\mathrm{Na}$ Biologia do Conhecer, a noção de acoplamento estrutural é essencial para definir a interação entre um ser vivo cognoscente e o seu meio. Dado que nessa teoria tanto o ser vivo como o sistema nervoso são sistemas fechados, a relação sujeitorealidade não é feita da captação de características de um mundo externo, mas de congruência entre a conduta do ser vivo e as mudanças estruturais do meio. No momento em que essa congruência se desfaz e as mudanças desencadeadas no indivíduo se tornam destrutivas, rompe-se a adaptação e ele morre. Essa relação não é de determinação, e sim de mútua especificação: o meio aciona a ontogenia de um sistema vivo, como consequência de uma deriva estrutural própria. Em contrapartida, ao 
observarmos essas mudanças de estado e atuarmos como descritores que especificam objetos, produzimos um mundo objetivo - uma realidade pela qual somos responsáveis. Por essa premissa, podemos afirmar que na epistemologia de Maturana subjaz um princípio ecológico: "Viver é deslizar na realização de um nicho" (Maturana R. et al, 1997, p. 87). Assim, sujeito e objeto, o ser e o real, não são categorias dadas, independentes e eternas, mas que se constituem no viver do observador, no seu "espaço relacional do conversar" (Maturana R. \& Verden-Zõller, 2004, p. 9). E se a conversação é uma relação de entrelaçamento entre linguagem e emoção, é o fundamento emocional que orienta a configuração das condutas, e sua definição é dada pelas vontades dos seus participantes em relação ao mundo que cada um deseja constituir e às consequências de seus atos.

\subsection{Critério de validação}

O conhecimento é ação efetiva, isto é, permite a um ser vivo adaptar-se e continuar sua existência em determinado meio. O critério dessa epistemologia é, portanto, vital: viver é fazer, é conhecer. No campo da ciência, o que valida o conhecimento não é a correspondência entre a explicação produzida e os objetos do mundo, mas a sua geração operacional: se o mecanismo explicativo for capaz de produzir os fenômenos que busca especificar, então é aceitável.

\subsection{Regularidade da realidade}

O mundo não é uma realidade absoluta, estática, pronta a ser descoberta, feita de fatos "lá fora" que captamos e armazenamos mentalmente. $\mathrm{O}$ ato de conhecer produz um mundo: "todo fazer é conhecer e todo conhecer é fazer" (Maturana R. \& Varela G., 1995, p. 67). Em seu acoplamento, ser vivo e ambiente vivem uma história de mudanças estruturais mútuas, numa deriva natural. Quando essas transformações se dão no âmbito de suas interações recorrentes, tratamos de ontogenia. Quando elas se mantêm ao longo de gerações, falamos de filogenia. Maturana deixa claro que a história dessas transformações não significa evolução como desenvolvimento progressivo em direção à otimização da exploração do ambiente. Não há princípios teleológicos a determinar as mudanças: "o existir nos ocorre como um presente contínuo em contínua mudança. Passado e futuro não estão vencidos, são modos de viver o presente" (Maturana R. \& Dávila Y., 2004, p. 103). Ambos são dimensões valiosas para referenciar a comunicação dos observadores, orientadas pelas suas emoções, preferências e vontades. Além disso, o fato de um sistema ser estruturalmente determinado não implica sua previsibilidade. Assim, a história não está prescrita: "somos o presente da história, como resultado atual de um porvir de transformações que ocorreram em torno da conservação do viver no conversar" (Maturana R. \& Verden-Zõller, 2004, p. 10).

\subsection{Neutralidade e objetividade}

Para Maturana, todo argumento racional tem fundamento numa premissa emocional, congruente com a vontade do sujeito que o enuncia. A racionalidade se funda em princípios, condições e premissas aceitas a priori. Mas o que vivemos origina-se dos desejos, do que queremos no viver-conviver, e não na lógica racional. Assim, a neutralidade não existe: "dizer-se neutro é só uma maneira de isentar-se da responsabilidade do mundo que configuramos em nosso viver na linguagem com outros seres humanos" (Graciano \& Magro, 1997, p. 17). Ao viver, realizamos uma cultura pela qual somos responsáveis, tanto na esfera local, da família quanto no âmbito social amplo. Conforme Maturana R. \& Dávila Y. (2004, p. 109), essa postura nos chama a decidir pelo tipo de relações que desejamos estabelecer: se a convivência com autonomia e respeito à participação, ou a obediência cega e dependência irresponsável que se isenta da autorreflexão.

A noção de objetividade é desdobrada por Maturana na "objetividade-sem-parênteses" e na “objetividade-entre-parênteses” (Maturana R., 2009, 
p. 42-48). Ambas implicam diferentes premissas sobre o observador no processo cognitivo. $\mathrm{Na}$ objetividade-sem-parênteses, pretende-se que o conhecer seja algo que ocorre independentemente das capacidades do observador: este "atua como se aquilo que ele distingue preexistisse à sua distinção, na suposição implícita de poder fazer referência a essa existência para validar seu explicar" (Maturana R., 2009, p. 45). Esse caminho explicativo pressupõe uma realidade transcendente que valida o conhecimento científico e o torna universal. Porém, a objetividade-entre-parênteses se baseia em princípios diferentes. Ela não nega a existência de objetos ou domínios independentes do sujeito, nem a possibilidade de conhecer a realidade, tampouco propõe que o conhecimento seja relativo. Admite apenas que nossa capacidade cognitiva seja constitutiva e dependente de nosso ser e, dessa forma, estamos sempre sujeitos ao erro: "depende de nós aceitarmos ou não uma certa reformulação da experiência [...] segundo um critério de aceitação que temos em nosso escutar e, portanto, [...] a validade das explicações que aceitamos se configura em nossa aceitação" (Maturana R., 2009, p. 47), não no objeto.

Para Maturana, essas duas posturas possuem diferentes implicações no desenvolvimento das relações humanas. Na objetividade-sem-parênteses, a explicação científica, colocando-se como uma verdade que independe de quem a propõe, pretendese universal e externa à experiência particular e, portanto, faz aos demais sujeitos uma petição de obediência e aceitação. Em outras palavras, ela nega o outro, assumindo uma natureza antissocial. A objetividade-entre-parênteses, por outro lado, cria uma dinâmica de aceitação mútua, orientada pela emoção fundante do social: o amor. Se na convivência os interlocutores erguem alguma objeção, o fazem responsavelmente, não em nome de uma verdade universal externa, mas do mundo que desejam configurar.

\subsection{Construção do conhecimento}

A Biologia do Conhecer integra e unifica as ciências da vida e as ciências sociais, pondo em evidência a natureza da condição social humana e seu fundamento biológico. Conforme ressalta Behncke C. (1995, p. 44), todo conhecimento é uma nova percepção por meio da qual observamos nosso mundo, afetando simultaneamente nosso ser - nossa estrutura interna - e nossa realidade social. Feito de explicações da experiência, o saber se dá na linguagem, o que Maturana sintetiza na máxima: "tudo o que é dito, é dito por alguém" (Maturana R. \& Varela G., 1995, p. 69). Admitindo que ajustar-se a um domínio do conhecer não exige que alguém saiba "tudo desde o começo" (Maturana R., 2009, p. 32), a Biologia do Conhecer faz um convite à aceitação e ao respeito por si e pelo outro. Assim, na construção de seus caminhos explicativos, o erro não é um obstáculo ao conhecimento, mas uma oportunidade legítima de mudança.

A ciência se constrói pela reformulação ou recriação de observações de um fenômeno, produzidas a partir de conceitos aceitáveis por uma comunidade de pessoas que partilham certos critérios de validação. Seu método consiste no seguir determinados passos, com o máximo grau de consistência, transparência e atenção à documentação: identificação do fenômeno a ser explicado; produção de uma hipótese explicativa; dedução de outros fenômenos a partir dessa hipótese; realização de observações adicionais.

\section{Bem-Viver}

Sumak Kawsay, Shiir Waras, Suma Qamaña, Teko Porã, Küme Mongen são alguns dos termos que traduzem diferentes cosmovisões dos povos originários da América Andina, relativos respectivamente às etnias Quéchua, Ashuar (Equador), Aymara, Guarani (Bolívia) e Mapuche (Chile). Essas concepções de mundo, com suas singularidades, compartilham um caráter holístico, 
podendo ser sintetizadas na compreensão de que o Bem-Viver envolve não apenas dimensões materiais, mas ainda o conhecimento, o reconhecimento sociocultural, a ética e a espiritualidade. Ele é vida plena, em harmonia e respeito mútuo com a Pachamama, mãe natureza da qual somos parte indissociável.

Conforme Esperanza Martínez, o Bem-Viver é uma produção de sujeitos históricos cuja conexão com a terra e a natureza persistem a despeito do sofrimento, da exploração e da destruição do ambiente (Sbardelotto, 2010). Nesse sentido, não se pode desconsiderar o caráter descolonizador e de resistência inerente a essa concepção, que vai além da luta por melhores condições sociais. Eduardo Gudynas considera o Bem-Viver um conceito em construção, tributário das epistemologias dos povos originários da América e que tem fecundado, em vários países, junto a diversos atores sociais, uma multiplicidade de posicionamentos. Para esse autor, "o Bem-Viver abre as portas a outras formas de falar, escrever ou pensar nosso mundo" (Gudynas, 2011). Ele tem se desdobrado no campo político e econômico como alternativa ao modelo capitalista de desenvolvimento, servindo de fundamento para construir um novo modo de vida que, em lugar da exploração da natureza, promova a convivência, a sustentabilidade, as soberanias e a solidariedade (Sbardelotto, 2010). Politicamente, tem provocado efeitos concretos, resultando na conversão da natureza em sujeito político de direitos - vide Constituições do Equador, de 2008, e da Bolívia, de 2009. Para além das cosmovisões dos povos originários latino-americanos, Gudynas (2011) reconhece aportes do ambientalismo biocêntrico, do feminismo radical e da descolonização do saber à configuração da epistemologia do Bem-Viver. Pela sua originalidade e fecundidade, é considerado "a mais importante corrente de reflexão que surgiu na América Latina nos últimos anos" (Gudynas, 2011), consistindo legítima inovação cultural contemporânea a partir de elementos tradicionais (Uzeda, 2009).

\subsection{Visão do conhecimento}

Na construção do conceito do Bem-Viver tem sido valorizada a noção plural do conhecimento, em que diferentes matrizes culturais são validadas sem se estabelecer uma hierarquia. Assim, não se busca uma visão autêntica e pura do Bem-Viver a partir de tradições dos povos originários. Como concepção de mundo, ele carrega uma visão do conhecimento para além da mera racionalidade. Abarca a interligação entre todas as entidades do cosmo, incluindo as dimensões materiais, intelectuais, emocionais, afetivas e espirituais. Esse conhecimento integral e holístico está profundamente vinculado à vida. É contextual, ambiental e territorial, construído no espaço do convívio entre as pessoas, os animais e o seu meio. Nessa perspectiva, não existe uma dualidade separando a sociedade da natureza: ambos são inextrincáveis e complementares. Para Xavier Albó, a melhor tradução para o Suma Qamaña seria "bom conviver", ressaltando o caráter coletivo e plural de uma cosmovisão que rejeita quaisquer exclusões (Albó, 2009).

\subsection{Relação sujeito-objeto}

Na concepção do Bem-Viver, não há objetos a serem explorados pelo ser humano: "tudo é vida, [...] todos somos uywas, criados da natureza e do cosmos" (Choquehuanca C., 2010). Nesse sentido, a natureza é também um sujeito e sobre ela não cabe propriedade, uso e destruição em benefício próprio. Portanto, as relações a serem construídas são de harmonia e solidariedade, em vez de hostilidade e competição, devendo-se “...superar a ideia cultivada na modernidade e santificada pela ciência ocidental [...] de que a natureza é algo hostil, que devemos dominar para sobreviver, e que aqueles que sobreviverão sempre serão os mais fortes" (Sbardelotto, 2010). A natureza está, dessa forma, incorporada na história como "parte inerente ao ser social” (Dávalos, 2008). Consequência dessa concepção é uma visão não-antropocêntrica do mundo. Aqui são complementares as noções de indivíduo e coletividade, particularidades e universalidade. 


\subsection{Critério de validação}

A validade do conhecimento é a própria realização do Bem-Viver: como epistemologia viva, ela deve produzir a "satisfação das necessidades, a conquista de uma qualidade de vida e morte dignas, o amar e ser amado e o crescimento saudável de todos, em paz e harmonia com a natureza, para o prolongamento das culturas humanas e da biodiversidade" (Gudynas, 2011, p. 5-6).

\subsection{Regularidade da realidade}

O Bem-viver desafia a ideia de transformação como progresso ilimitado e evolução linear da história. Em seu lugar, prevalece a autonomia e liberdade para que as capacidades e potencialidades reais dos indivíduos e coletividades floresçam e se ampliem, contrapondo-se a qualquer tipo de dominação ou teleologia. Essa ideia é traduzida na concepção de qamir qamaña, traduzida por Ramírez G. (2010) como "a doçura de ser sendo".

\subsection{Neutralidade e objetividade}

O Bem-Viver suspende a noção de objetividade, na medida em que quebra o dualismo humano-natureza e a suposição de uma separação entre o sujeito e seu meio. Da mesma forma, ao buscar a harmonização de relações, baseadas no compromisso ético dos indivíduos e coletividades e na sua responsabilidade para com o ambiente e as futuras gerações, não pode aceitar a neutralidade do conhecimento. Este se dirige à produção da justiça social e da igualdade.

\subsection{Construção do conhecimento}

A própria construção do conceito de Bem-Viver tem admitido aportes de inúmeras epistemologias, sejam elas visões tradicionais dos povos originários, suas recriações filosóficas contemporâneas ou as contribuições de vertentes críticas ocidentais. Cultiva-se o pluralismo de pensamento e métodos, entendendo que "existem ênfases diferentes e é bom que seja assim, já que isso em si mesmo é o reflexo de sociedades diversas e multiculturais onde todas essas posturas existem e cada uma delas é necessária para se conseguir transformações substantivas" (Gudynas, 2011). $\mathrm{Na}$ construção do Bem-Viver, os diversos saberes dos povos originários desempenham papel fundamental e não cabe eleger um deles como representativo do conjunto, tampouco produzir uma definição consensual que aplaine as diferentes potencialidades explicativas da realidade. Prevalece o questionamento dos ideais da Modernidade a partir da produção de novas ideias, discursos e práticas, em direção à geração de modos de vida e conhecimento alternativos. Subverte-se a Modernidade, portanto, como epistemologia mesma, uma vez que se supera a necessidade de gerar um conhecimento que se pretenda universal, validado pela unidade em torno de discursos disciplinares e baseado na identidade fixa do sujeito que o produz, para aceitar a possibilidade de convivência e trânsito entre diferentes visões na fertilização de um conhecimento multiversal.

\section{Ubuntu}

Ubuntu é um sistema "afroperspectivista de resistência e configuração dos valores humanos [... caracterizado por] uma possibilidade de existir junto com outras pessoas de forma não egoísta" (Noguera, 2011, p. 147). O termo tem origem em comunidades da língua Bantu e é partilhado por quatro grupos étnicos: ndebele, swati, xhosa e zulu. É uma contração da máxima umuntu ngumuntu ngabantu: uma pessoa é uma pessoa por meio de outras pessoas. Como modo de vida, Ubuntu é praticado na maior parte da África, do deserto da Núbia ao Cabo da Boa Esperança e do Senegal a Zanzibar. Para Desmond Tutu, ele abarca a hospitalidade, o cuidado com os outros e a disposição em se sacrificar pelo bem alheio (Nabudere, 2005). Uma vez que a humanidade de alguém é inextrincável da dos demais, ela só se realiza em comunidade, via pertencimento. 
Como epistemologia, Ubuntu é uma filosofia de libertação e resistência ao discurso ocidental que nega o aporte dos povos da África ao saber e à civilização. Ele está na raiz do ser e dos sistemas de pensamento e crenças que refletem a experiência vivida dos africanos, bem como sua compreensão da realidade, extremamente sofisticada em termos sociais e políticos. O colonialismo europeu, ao entrar em contato e conflito com tais cosmovisões, desvalorizou-as como primitivas, ineficazes e inapropriadas, marginalizando-as e substituindoas pelos seus próprios sistemas formais de conhecimento e ensino. Embora estes tenham sido implantados globalmente como universais, a educação tradicional africana não só era viável, apropriada e útil nos contextos comunitários pré-coloniais, como as epistemologias que eles carregam ainda podem conformar os sistemas contemporâneos na África (Wright \& Abdi, 2012, p. 4). Nessa esteira, diversos estudiosos sustentam que as contribuições do Ubuntu podem ser aproveitadas por toda a humanidade, a partir da aplicação consciente de seus valores.

\subsection{Visão do conhecimento}

Noguera (2011) demonstra que o conhecimento, pela óptica Ubuntu, é um processo essencialmente humanizador, na medida em que a desumanização impede a auto-reflexividade e a capacidade de usufruirmos nossas potencialidades. Ele supõe um modo de viver e existir comunitário, antirracista e policêntrico. Inserido na comunidade, trabalhando em prol de si e dos demais, o ser humano desenvolve a criatividade e a inventividade associadas ao saber. A capacidade de partilha manifesta-se como generosidade na cooperação em que os resultados obtidos revertem no proveito coletivo. Ela expressa a ideia de que o saber decorre de múltiplas trocas e aprendizados e, portanto, é fruto de um polidiálogo, em que não se busca o consenso, mas um múltiplo ouvir-falar.

\subsection{Relação sujeito-objeto}

No Ubuntu, em lugar da relação sujeitoobjeto convencional, temos a humanização por meio da produção do mundo na convivência inclusiva e abrangente, da qual fazem parte os aspectos manifestos e imanifestos da realidade, vivos e não-vivos, materiais e imateriais, humanos e não-humanos, em suma: a singularidade e a totalidade. Ramose (2002) esclarece que o Ubuntu supõe a existência de Umuntu, organismo vivo que efetivamente percebe e está consciente de sua própria existência, assim como a dos outros. É liberando a fala do ser e pondo em diálogo o ser-sendo (totalidade) com o ser manifesto (singular) que Umuntu produz sua racionalidade. Integrado à totalidade, Umuntu é a manifestação concreta e emergente de umu, o ser-sendo humano, simultaneamente homo loquens e homo sapiens. A totalidade e a singularidade do ser humano são aspectos indivisíveis, em contínuo movimento e, por isso, não fragmentáveis. Nabudere (2005) acrescenta que Umuntu é o ser criativo que produz seu próprio mundo, emergindo e transformandose constantemente. Em sua atividade, busca gerar as condições de existência com os outros seres, tornando-se um ser com outros, que é ao estar junto, na convivência.

\subsection{Critério de validação}

A verdade é a base para o agir humano e deve ser encontrada na experiência histórica vivida, não em abstrações filosóficas com pouco significado na vida real. Essa experiência é, essencialmente, partilhada no polidiálogo, não exigindo um consenso construído na disputa. Abrangente, a verdade não se limita à materialidade da existência, tampouco à sua evidência: como afirma Nabudere (2005), o fato de o desconhecido ser desconhecido não faz dele inacreditável. 


\subsection{Regularidade da realidade}

O movimento (ser-sendo) é o princípio do ser. A palavra Ubuntu é composta do prefixo Ubu, que significa totalidade, e da raiz $n t u$, singularidade. Nas línguas Bantu, ntu também designa o ser humano. Ubu evoca a qualidade imanifesta do ser-sendo, como um ser encoberto que tende a se revelar, num descobrimento contínuo e incessante, por meio do $n t u$, as inúmeras manifestações concretas do ser, nos seus modos de ex-istência particulares. Tudo que é percebido como um todo é uma total-idade "que ex-iste e per-siste em direção ao que ainda está para ser" (Ramose, 2002). Não há separação ou oposição entre $u b u$ e $n t u$, como dimensões ou aspectos da realidade. Assim, ontologia e epistemologia coincidem nessa categoria indivisível.

\subsection{Neutralidade e objetividade}

Como cada pessoa vê o mundo de maneira própria, nunca podemos nos colocar totalmente no lugar do outro e ver o mundo como ele. Por isso, Swanson (2007) propõe que a neutralidade dê lugar à solidariedade, e a objetividade, à alteridade, que se realiza simultaneamente como autonomia e cooperação. Assim, na investigação da realidade, o Ubuntu dissolve as dicotomias euoutro, comprometendo o pesquisador com a escuta e ressaltando sua responsabilidade na produção de um saber que promova a transformação e a transcendência. Na construção do conhecimento, a verdade deve expressar a vontade coletiva em equilíbrio e a forma como indivíduos e comunidades se dirigem uns aos outros. Além disso, o saber deve combater as distinções colonialistas, voltando-se às comunidades e ao seu empoderamento.

\subsection{Construção do conhecimento}

Ramose (2011) lembra que um dos pilares do colonialismo foi a crença de que somente os homens ocidentais eram naturalmente dotados de razão. Sobre essa ideologia, que negava o estatuto humano dos africanos, foi possível questionar a existência de sua filosofia e estabelecer o pensamento e o método científico europeus ocidentais como universais. Tendo em vista que a ideia de universalidade se assentava na concepção - já desacreditada - de que o cosmo possui um centro, o filósofo sul-africano propõe que passemos à pluriversalidade.

O Ubuntu configura uma epistemologia complexa, que reconhece a interconectividade e interdependência de tudo e constitui o conhecimento como um terreno de encontro. Em lugar de um saber linear, fragmentado, materialista e individualista, ele se propõe como um paradigma de enação, circular, orgânico coletivista. Ele persegue a interpretação, a expressão, o entendimento e a harmonia moral e social, mais que a verificação, a racionalização, a previsibilidade e o controle. Wright e Abdi (2012) sustentam que é justamente nessa inclusividade que se funda a validade discursiva e a urgência dos sistemas de conhecimento e das tradições filosóficas africanas.

\section{Sociomuseologia mirada do Sul}

O fazer museológico pode ser interpretado como um processo de natureza cognitiva. Trata, em síntese, de observar a realidade de um determinado grupo social, identificando nela seu patrimônio, isto é, os elementos e formas de organização essenciais ao seu modo de vida, comprometendo-se com seu uso e preservação, no interesse das gerações atuais e futuras. Sendo assim, e considerando que "as teorias científicas [...] tradicionalmente apoiam-se em pressupostos ontológicos e epistemológicos, não raro de forma implícita e inconsciente" (Graciano \& Magro, 1997, p. 17), podemos inferir que em cada teoria museológica subjazem premissas sobre o fazer científico, o conhecimento, a verdade, a relação sujeito-objeto, a realidade, a objetividade e a neutralidade. Será interessante estender o exercício de análise aqui empreendido às diferentes abordagens da Teoria Museológica, sobretudo, porque de tais concepções desdobram-se implicações concretas na configuração das instituições e no 
exercício profissional dos museólogos. No âmbito deste artigo, focamo-nos em buscar abordagens que possam fortalecer criticamente e fertilizar o campo da Sociomuseologia. A Biologia do Conhecer, o Bem-Viver e o Ubuntu comungam o fato de se caracterizarem como reflexões simultaneamente epistemológicas e filosóficas que concebem o conhecer humano como um fazer humanizador, em congruência e harmonia com a vida. Além disso, carregam consigo componentes fundamentais para se conceber processos educativos partilhados.

Assim, ao investigar os fundamentos epistemológicos da Educação Museal, propomos que o processo museológico social pode ser definido como um processo cognitivo específico, isto é, um certo fazer-conhecer cujo objeto e produto é o patrimônio comunitário. A partir deste breve exercício de cruzamento entre a Biologia do Conhecer, o Bem-Viver e o Ubuntu, podemos eleger algumas de suas características essenciais:

a) o elemento social, traduzido pela aceitação humilde do outro no pertencimento entendido como participação e protagonismo coletivo, que simultaneamente nega as hierarquias e respeita as singularidades e que permite entender toda relação de cooperação como um exercício ético espontâneo e uma livre expressão da vontade dos sujeitos, sendo a exclusão um equívoco extraordinário a ser superado. Quer pela noção de acoplamento entre o ser vivo e seu meio, quer pela ideia da Pachamama como um sujeito de direitos, ou ainda pela inclusividade Ubuntu, a concepção do social não é antropocêntrica, pois para haver o humano é preciso haver também congruência e harmonia com o ambiente que o rodeia;

b) a recorrência ou duração, fundada na convivência, na vontade e no compromisso entre os participantes, incluindo gerações passadas e futuras, que permite o surgimento da linguagem comum e da reflexividade sobre o patrimônio; c) a natureza comunicativa e discursiva da produção do patrimônio, em que o nomear é um processo dialógico e polifônico de produção de sentidos negociados, sem um centro emanante, unificador ou validador do discurso;

d) o caráter empirista processual, num sentido humanizador e libertário, que se manifesta não como a conformação do patrimônio integral a certas categorias preestabelecidas externamente à realidade comunitária, tampouco como a evolução dos procedimentos de preservação e comunicação em direção a um nível de excelência dado por normas e padrões de atuação, mas como a deriva permanente de propostas de ação e de sentido para a experiência;

e) o critério vital de validação, isto é, o entendimento de que, expressando a congruência com a vida, o reconhecimento/ produção do patrimônio imediatamente compromete a coletividade num sentido ético com sua manutenção e seu cuidado.

Cremos que sem esses elementos não se pode conceber adequadamente um processo de educação museal, isto é, um processo museológico partilhado com uma comunidade, que se pretenda humanizador.

Temos, pois, fundamentos para afirmar que, em termos epistemológicos, nem toda Museologia é social, no sentido que Maturana concede a esse termo. Há, também, museologias antissociais, fundadas na negação do outro. A Museologia Social é estritamente aquela em que os participantes, em sua diferença e diversidade, são aceitos como legítimos outros no fazer museal. Profissionais e comunidades encontram-se na convivência que permite o emergir de uma linguagem comum. Nesse linguajar, humilde e solidariamente se vão constituindo observadoresdescritores da experiência coletiva, afinando suas percepções sobre a realidade vivida e propondo caminhos explicativos daquilo que nos permite ser o que somos e simultaneamente, o que queremos 
nos tornar. Em última instância, na Museologia Social estamos constantemente a buscar conhecer e conservar as relações que nos humanizam, elegendo, para nos lembrar, elementos materiais e imateriais que as condensam. Devir patrimônio, eis o que perseguimos: fazer-conhecer a nós mesmos, em comunhão com os outros, com o mundo, com a vida - nossa transcendência imanente.

Como campo vivo de estudos e intervenção social, a Sociomuseologia é permanentemente instigada a expandir e aprofundar conceitos e práticas. Se continua relevante o propósito enunciado pela comunidade museológica em 1972, na Mesa Redonda de Santiago do Chile - de firmar o compromisso dos museus com a vida, a dignidade humana e a justiça social - no cotidiano das instituições, isso é em alguma medida realizado e em alguma medida negado. Nos cenários de opressão, aflora sempre uma resistência; e, onde quer que a liberdade se realize, ainda assim será possível ampliá-la. Por meio da crítica auto-reflexiva e do deslocamento das centralidades tomadas como garantidas, descobrimos os pontos cegos que nos impedem de perceber as exclusões e os limites de nosso fazer-conhecer. Assim, olhar para o campo desde a perspectiva dos povos originários do Sul pode contribuir para sua descolonização, possibilitando-nos cultivar outras derivas de práxis propícias a reinvenções do fazer museal.

\section{Referências}

Albo, X. (2009). "Suma qamaña = el buen convivir". Revista Obets, (4): 25-40.

Behncke C., R. (1995). Ao pé da árvore. Prefácio. In: Maturana R., H.; Varela G., F. A árvore do conhecimento: as bases biológicas do entendimento humano. Campinas: Editorial Psy, pp. 9-51.

Carvalho, J. M. (2010). A visão de ciência e de metodologia de pesquisa em diferentes perspectivas e/ou "escolas" filosóficas. Cadernos de Pesquisa em Educação PPGEUFES, v. 16 (32): 8-28.

Choquehuanca C., D. (2010). "Hacia la reconstrucción del Vivir Bien". América Latina en Movimiento, ALAI, (452): 6-13.

Dávalos, P. (2008). Reflexiones sobre el sumak kawsay (buen vivir) y las teorías del desarrollo. ALAI (Agencia Latino Americana de Informaciones). Disponível em $<$ http://alainet. org/active/25617>. Acesso em 23 abril 2016.

Graciano, M.; Magro, C. (1997). Introdução. In: MATURANA R., H. et al. A ontologia da realidade. Belo Horizonte: Ed. UFMG, pp. 17-30.

Gudynas, E. (2011). "Buen vivir: Germinando alternativas al desarrollo". América Latina em Movimento - ALAI, (462): 1-20.

Martins, L. C. (2011). A constituição da educação em museus: o funcionamento do dispositivo pedagógico museal por meio de um estudo comparativo entre museus de artes plásticas, ciências humanas e ciência e tecnologia. 390p. Tese (doutorado) - São Paulo: Faculdade de Educação. Universidade de São Paulo.

Maturana R., H. (2009). Emoções e linguagem na educação e na política. Belo Horizonte: Editora UFMG. 
Maturana R., H.; Dávila Y, X. (2004). “Conferência: Ética e desenvolvimento sustentável caminhos para a construção de uma nova sociedade". Psicologia \& Sociedade, Porto Alegre, v. 16 (3): 102-110. Disponível em: $<$ http://www.scielo.br/ scielo.php?script=sci arttext\&pid=S0102-71822004000300013\&lng $=$ pt $\&$ tlng $=$ pt. $>$. Acesso em: 10 jan. 2016.

Maturana R., H. et al. (1997). A ontologia da realidade. Belo Horizonte: Ed. UFMG.

Maturana R., H.; Varela G., F. (1995). A árvore do conhecimento: as bases biológicas do entendimento humano. Campinas: Editorial Psy.

Maturana R., H.; Verden-Zõller, G. (2004). "Amar e brincar: fundamentos esquecidos do humano do patriarcado à democracia”. São Paulo: Palas Athena.

Nabudere, D. (2005) Ubuntu philosophy: memory and reconciliation. Disponível em University of Texas Libraries: <http://hdl.handle. net/2152/4521>. Acesso em 3 de Abril de 2016.

Noguera, R. (2011). "Ubuntu como modo de existir: elementos gerais para uma ética afroperspectiva". Revsita $A B P N$ 3, (6): 147150.

Ramírez G., R. (2010). Socialismo del sumak kawsay o biosocialismo republicano. In: Los nuevos retos de América Latina. Socialismo y sumak kawsay. Quito, SENPLADES, pp. 55-74.

Ramose, M. (2002). The ethics of ubuntu. In: Coetzee, P.; Roux, A. (eds.) The African Philosophy Reader. New York: Routledge, pp. 324-330.

Ramose, M. (2011). "Sobre a legitimidade e o estudo da filosofia africana”. Ensaios filosóficos, v. 4: 6-25.
Sbardelotto, M. (2010). Sumak kawsay. Nem melhor, nem bem: viver em plenitude. Entrevista especial com Esperanza Martínez. Instituto Humanitas Unisinos On-Line, Disponível em <http://www.ihu.unisinos. br/entrevistas/34622-sumak-kawsay-nemme...-viver-em-plenitude-entrevista-especialcom-esperanza-martinez->. Acesso em 27 de dezembro de 2015.

Swanson, D. (2007). "Ubuntu: An African contribution to (re)search for/with a 'humble togetherness"'. Journal of Contemporary Issues in Education. v. 2 (2): 53-67, Disponível em $<$ https://ejournals.library.ualberta.ca/index. $\mathrm{php/JCIE/article/view} \mathrm{/1028>.} \mathrm{Acesso} \mathrm{em} 27$ dez. 2015.

Uzeda V., A. (2009). Suma qamaña. Visiones indígenas y desarrollo. Traspatios, Cochabamba, v. 1:33-51.

Wright, H.; Abdi, A. (2012). Introducing the dialectics of African education and western discourses: appropriation, ambivalence, and alternatives. In: Wright, H.; Abdi, A. (Eds.) The dialectics of African Education and western discourses: counter-hegemonic perspectives. New York: Peter Lang, p. 1-12. 